JOURNAL OF THEORETICAL

AND APPLIED MECHANICS

59, 4, pp. 637-647, Warsaw 2021

https://doi.org/10.15632/jtam-pl/141447

\title{
CAUSE INVESTIGATION OF METRO CORRUGATION IN VEHICLE BRAKING SECTION OF TRACK
}

\author{
ZHIQIANG WANG*, ZhenYu LeI \\ Institute of Rail Transit, Tongji University, Shanghai, China \\ e-mail*:1733359@tongji.edu.cn
}

\begin{abstract}
In order to study the cause of rail corrugation in the tangential braking section near the metro entrance, a transient rolling contact model of three-dimensional solid wheelset-track was established by using the finite element software ABAQUS, and the corrugation phenomenon was analyzed in the time-domain and frequency-domain based on the field measurement. The results show that the unstable friction self-excited vibration of the wheelset-track system is the fundamental cause of rail corrugation in the measured section, and it is precisely because of the "saturated-unsaturated" periodic characteristic of the wheel-rail creep force that ultimately promotes the formation of rail corrugation.
\end{abstract}

Keywords: metro, braking section, rail corrugation, transient rolling contact model, friction self-excited vibration

\section{Introduction}

Rail corrugation is a kind of periodic wavy wear phenomenon occurring on the rail surface, which is one of the most common rail diseases in metro lines (Wen, 2006). The research on rail corrugation can be traced back to the last century, and formation mechanisms of different types of rail corrugations are analyzed by theoretical methods, numerical simulation and field tests. Due to different operation conditions of metro, the phenomena of rail corrugation are different, and there is no unified and effective theory to explain the mechanisms of different rail corrugations. The existence of rail corrugation will not only lead to aggravation of structural vibration of the track and vehicle, deterioration of fastener damage and an increase of vehicle running noise, but also will affect the riding comfort of passengers and service life of the track and vehicle components (Li et al., 2013; Cai et al., 2019). In order to prevent and control rail corrugation fundamentally, it is necessary to conduct a comprehensive investigation on the causes of rail corrugation in combination with the actual situation of metro lines.

The phenomena of rail corrugation are very complex, so there are many publications on the causes of rail corrugation around the world. Grassie and Kalousek (1993) summarized the research situation of rail corrugation, divided generation mechanisms of rail corrugation into wavelength-fixed and material damage mechanisms, and put forward the classification, causes and countermeasures of rail corrugation based on the above mechanisms. After that, Grassie further revised the classification and causes of rail corrugation proposed in the literature (Grassie, 2009), believing that all types of rail corrugations were caused by the frequency-fixed mechanism rather than the wavelength-fixed mechanism. Wang and Wu (2020a,b) studied the influence of vibration interference between multi wheels and a resilient track on rail corrugation. By combining the time-domain model of a discrete support slab track, an unsteady two-dimensional wheel-rail tangential contact model and a long-term wear model, the growth process of rail corrugation under the interaction of the single wheel-rail and multi wheel-rail was simulated. The 
results showed that the low-frequency standing wave between wheels was the main cause of rail corrugation, and the dependence of wavelength on the wheelbase constituted the wavelength-fixed characteristic of rail corrugation. Based on the vibration theory of the track structure and combined with field investigation and measurement, Li et al. (2016) discussed the causes of rail corrugation on the trapezoidal sleeper track, and analyzed the internal relationship between the inherent characteristics of the track structure and rail corrugation by using the finite element model. The results indicated that the vertical and transverse bending vibrations of the rail relative to the sleeper were easily caused by the reciprocating operation of vehicles, which aggravated the wheel-rail stick-slip vibration and accelerated the formation and development of rail corrugation. Li et al. (2017) studied the influence of vibration characteristics of a resilient track system on rail corrugation formation by establishing the vehicle-track system dynamic model, and considered that rail wear caused by transverse slipping between the wheel and rail and vertical vibration of the track structure might be the main cause of rail corrugation. Liu et al. $(2015,2016)$ investigated and tested the rail corrugation in the shear damper fastener section of Beijing metro, and found that the wheel-rail resonance of $200-400 \mathrm{~Hz}$ was the main reason of rail corrugation. Meantime, the measures to reduce the corrugation were put forward, such as adding rubber pad in the shear damper fastener and installing a frequency modulation rail damper on the rail waist. The test results illustrated that the above measures could effectively control the development of rail corrugation. By establishing the three-dimensional solid finite element model of the train wheelset-track coupling and combining with the modal test results of the wheelset, Pan et al. (2020) found that the transverse bending vibration of the rail caused by the wheelset transverse modal characteristics of $200-400 \mathrm{~Hz}$ under the condition of wheel-rail coupling was one of the reasons for the formation of rail corrugation with the wavelength of 40-60 $\mathrm{mm}$ in the measured section. Yao et al. (2018) studied generation of wear-type corrugation in rail micro contact patch, put forward the micro wavelength-locked expansion mechanism, and verified the mechanism through experiments. The publications (Wu et al., 2019, 2020a,b; Chen et al., 2010, 2020; Cui et al., 2016, 2017, 2018, 2019) proposed the view that the friction self-excited vibration between the wheel and rail caused rail corrugation when the wheel-rail creep force reached saturation. This view held that the friction self-excited vibration between the wheel and rail caused the same frequency variation of wheel-rail normal force, and the friction work between the wheel and rail would fluctuate periodically with the variation of the normal force, which led to rail corrugation eventually. Besides, Kurzeck (2011) also put forward a similar view.

Through literature investigation, it can be found that up to now, most of the publications on rail corrugation are mainly carried out in the frequency-domain, while the analysis on the generation and evolution processes of rail corrugation in the time-domain is less. Some publications only analyzed the time-domain dynamic responses of the wheel-rail system (or vehicle-track system), and did not directly get the occurrence state of rail corrugation. Moreover, more importantly, the time-domain dynamic responses of the wheel-rail system (or vehicle-track system) are not directly related to the formation of rail corrugation (Wu et al., 2020a,b). Therefore, there are still some deficiencies in the existing publications. Based on that, this paper takes the rail corrugation on the Cologne egg fastener track in a tangential section near the entrance of a metro line in Shanghai as the research object. Firstly, the characteristic wavelength and frequency of rail corrugation are obtained by analyzing the measured data. Then, referring to the actual line situation, the finite element software ABAQUS is used to establish a three-dimensional solid wheelset-track transient rolling contact model and carry out the simulation. Finally, according to the calculation results, the cause of rail corrugation is analyzed in the time-domain and frequency-domain. Compared with the previous publications, the difference of this paper is that the occurrence state of rail corrugation is reproduced in the time-domain, and the calculation results are in good agreement with the field measurement. 


\section{Methodology}

\subsection{Wheelset-track transient rolling contact model}

The measured corrugation section of Cologne egg fastener track on the tangential line is located near the entrance of the metro station. The motor cars of the running train in this section are in the braking state, with a large creep force, and the wheels may slip. Referring to (Wang and Lei, 2020), the finite element model of wheelset-track three-dimensional transient rolling contact is established by using ABAQUS, as shown in Fig. 1, so as to simulate the vehicle-track system on the actual metro line. It should be noted that although (Wang and Lei, 2020) and the current paper adopt the similar finite element method, the emphases of the two papers are completely different. Wang and Lei (2020) mainly studied dynamic characteristics of a wheel-rail system under the excitation of corrugation, while this paper focuses on the formation mechanism of corrugation. The wheel-rail interaction in the corrugation section belongs to the category of high frequency, and the high frequency dynamic responses of the vehicle-track coupling system mainly depend on the flexibility of the wheelset and track (Chaar and Berg, 2006), so all above the components of the primary suspension of the vehicle system are simplified as mass points connected with the axle through the primary suspension, as shown in Fig. 1a. A schematic diagram of the wheelset-track finite element model is shown in Fig. 1b. The wheelset model includes two wheels and one axle, and the track model includes the rail, fastener and track slab. The primary suspension and fastener parts are simulated by spring-damper elements, and the stiffness and damping in three directions can be considered. The supporting effect of the foundation on the track structure is simulated by the grounding spring. In the wheelset-track transient rolling contact model, the track length is $36 \mathrm{~m}$ and the fastener spacing is $0.6 \mathrm{~m}$. The relevant parameters of each component are shown in Table 1 (Lei and Wang, 2020; Lei et al., 2019).
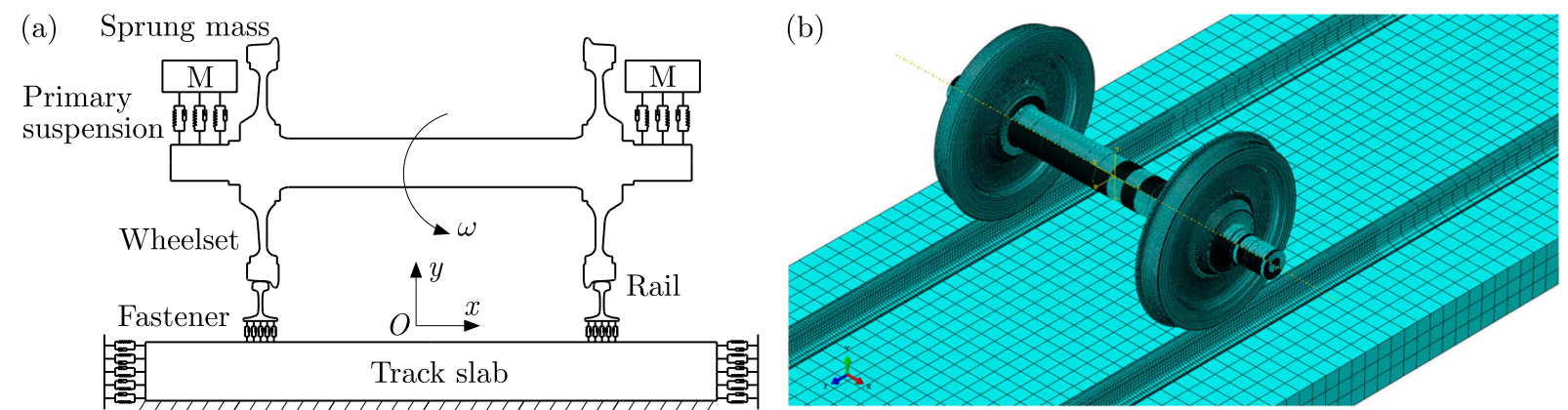

Fig. 1. Finite element model and mesh generation diagram: (a) model structure diagram, (b) finite element model and mesh generation diagram

For the wheelset-track transient rolling contact model, both wheelset and rail are discretized into 8-node hexahedral elements. The rail type is CHN60, the rail cant is 1:40, and the wheel tread type is LM worn tread. The surface to surface contact algorithm based on the penalty function is used to solve the contact behavior between the wheel and rail, and the coefficient of friction is 0.4. In order to ensure the accuracy of the model solution and reduce the calculation cost of the model as much as possible, an uneven mesh is used in the meshing of the wheel and rail, that is, the mesh at the wheel-rail contact zone is fine (the element size is $2 \mathrm{~mm}$ ), which is used to solve the wheel-rail contact, and the mesh away from the wheel-rail contact zone is coarse (the element size is $100 \mathrm{~mm}$ ). The track slab is also simulated by 8 -node hexahedral elements, and the mesh size is $100 \mathrm{~mm}$. The total number of nodes and the total number of elements of the wheelset-track transient rolling contact finite element model are $836.9 \cdot 10^{4}$ and $735.6 \cdot 10^{4}$, respectively. The boundary conditions of the model are as follows: symmetrical constraints are 
Table 1. Parameters of each component of the model

\begin{tabular}{|c|c|c|}
\hline \multicolumn{2}{|r|}{ Parameter } & Value \\
\hline \multicolumn{2}{|r|}{ Sprung mass $[\mathrm{kg}]$} & 8720 \\
\hline \multirow{6}{*}{$\begin{array}{c}\text { vehicle } \\
\text { primary } \\
\text { suspension }\end{array}$} & vertical stiffness $[\mathrm{N} / \mathrm{m}]$ & $1.3 \cdot 10^{6}$ \\
\hline & transverse stiffness $[\mathrm{N} / \mathrm{m}]$ & 547000 \\
\hline & longitudinal stiffness $[\mathrm{N} / \mathrm{m}]$ & 547000 \\
\hline & vertical damping $[\mathrm{Ns} / \mathrm{m}]$ & 2400 \\
\hline & transverse damping $[\mathrm{Ns} / \mathrm{m}]$ & 1500 \\
\hline & longitudinal damping $[\mathrm{Ns} / \mathrm{m}]$ & 1500 \\
\hline \multicolumn{2}{|r|}{ Mass of wheelset $[\mathrm{kg}]$} & 1420 \\
\hline \multirow{5}{*}{$\begin{array}{c}\text { material of } \\
\text { wheelset } \\
\text { and rail }\end{array}$} & elastic modulus $[\mathrm{Pa}]$ & $2.059 \cdot 10^{11}$ \\
\hline & plastic modulus [Pa] & $2.1 \cdot 10^{10}$ \\
\hline & yield strength $[\mathrm{Pa}]$ & 800 \\
\hline & density $\left[\mathrm{kg} / \mathrm{m}^{3}\right]$ & 7800 \\
\hline & Poisson's ratio & 0.3 \\
\hline \multirow{6}{*}{$\begin{array}{c}\text { fastener } \\
\text { part }\end{array}$} & vertical stiffness $[\mathrm{MN} / \mathrm{m}]$ & 12.07 \\
\hline & transverse stiffness $[\mathrm{MN} / \mathrm{m}]$ & 7.58 \\
\hline & longitudinal stiffness [MN/m] & 7.58 \\
\hline & vertical damping $[\mathrm{Ns} / \mathrm{m}]$ & 1361 \\
\hline & transverse damping $[\mathrm{Ns} / \mathrm{m}]$ & 974 \\
\hline & longitudinal damping $[\mathrm{Ns} / \mathrm{m}]$ & 974 \\
\hline \multirow{3}{*}{$\begin{array}{c}\text { material of } \\
\text { track slab }\end{array}$} & elastic modulus [Pa] & $3.25 \cdot 10^{10}$ \\
\hline & density $\left[\mathrm{kg} / \mathrm{m}^{3}\right]$ & 2400 \\
\hline & Poisson's ratio & 0.24 \\
\hline \multirow{2}{*}{ foundation } & supporting stiffness $[\mathrm{N} / \mathrm{m}]$ & $1.7 \cdot 10^{8}$ \\
\hline & supporting damping $[\mathrm{Ns} / \mathrm{m}]$ & $3.1 \cdot 10^{4}$ \\
\hline
\end{tabular}

set at the $z$-direction of two ends of each rail and the track slab to reduce the influence of the stress wave reflection on the calculation results; transverse constraints are set at the $x$-direction of two sides of the track slab; no constraints are set at the wheelset. The gravity and the driving force of the wheel axle are considered in the load application of the model.

\subsection{Solution of the model}

The instantaneous dynamic analysis is used to solve the model, which mainly includes explicit time integration and implicit time integration. The difference between them lies in different ways of solving node acceleration. The explicit time integration method solves the node acceleration directly through node calculation, while the implicit time integration method uses an iterative approach to solve equilibrium equations of the system. When the time increment is less than one tenth of the vibration period of the system concerned, the implicit time integration algorithm can obtain more reliable results (Cui et al., 2016). Therefore, the implicit solver ABAQUS/Standard is selected to analyze dynamic responses of the wheel-rail system.

Since the implicit time integration method obtains the acceleration of the node at the end of the incremental step by solving the equilibrium equations of the system, the method is unconditionally stable. In the process of transient dynamic analysis of the wheel-rail system, the frequency of rail corrugation is generally in the range of $20-1200 \mathrm{~Hz}$, so the integral step-size is set as $0.00005 \mathrm{~s}$. 


\subsection{Measured corrugation}

According to the actual measurement of the metro line, the wavelength of rail corrugation on the Cologne egg fastener track section is about $70-80 \mathrm{~mm}$, and the running speed of vehicles in this section is about $50 \mathrm{~km} / \mathrm{h}$, so the corresponding characteristic frequency of rail corrugation is about $174-198 \mathrm{~Hz}$. The picture of corrugation on-site is shown in Fig. 2.

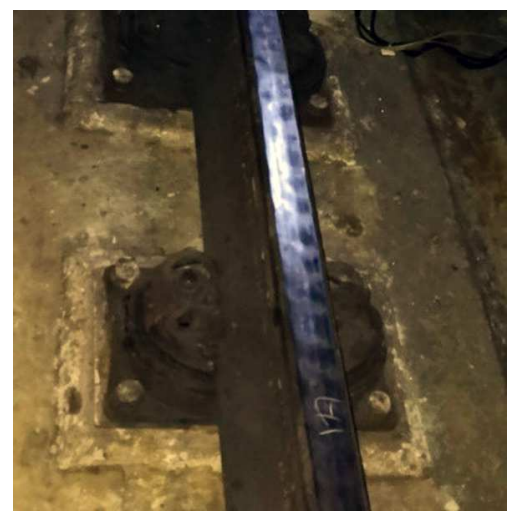

Fig. 2. Picture of corrugation on-site

\section{Cause analysis of rail corrugation}

\subsection{Time-domain characteristic analysis}

Referring to the actual line situation, the speed of the wheelset is set to be $50 \mathrm{~km} / \mathrm{h}$, the movement time is set to be $0.8 \mathrm{~s}$, and the initial position of wheel-rail contact is $12.4 \mathrm{~m}$ away from the rail end. The movement of the wheelset is driven by the rotation speed applied to the axle. Because wear of the rail surface material is closely related to relative slipping of corresponding nodes, that is, only when the nodes slip, the corresponding wear will occur. Therefore, this Section first studies the phenomenon of rail surface slipping. Assuming that the rail surface is smooth without any initial irregularity, the slipping zone distributions of left and right rails on the Cologne egg fastener tangential track can be obtained through simulation and calculation, as shown in Figs. 3 and 4.

(a)

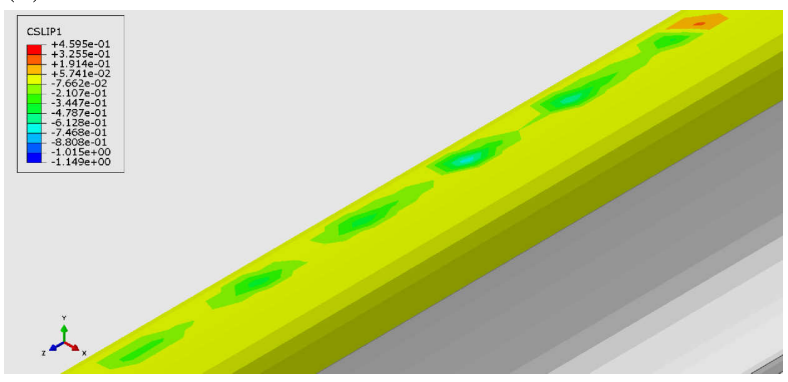

(b)

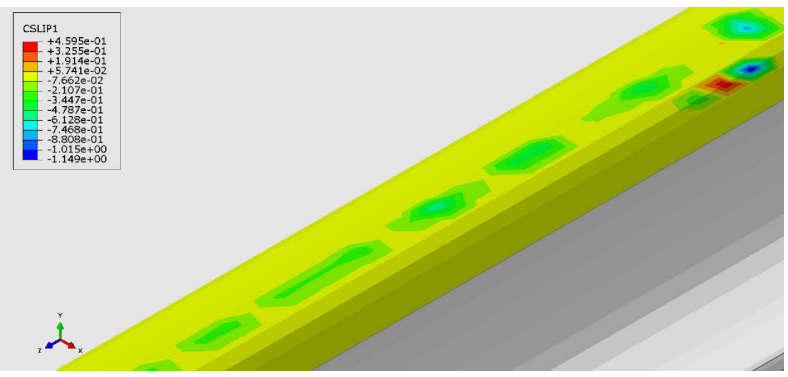

Fig. 3. Distribution of the slipping zone in the tangential direction of the rail section: (a) left rail, (b) right rail

It can be seen from Figs. 3 and 4 that in the process of the vehicle decelerating from the initial operation state to the static state near the entrance of the metro line, a quasi-periodic slipping zone will occur in the contact surface between the wheel and rail, including the tangential direction of the rail section and the vertical direction of the rail section (the direction of wheelset 
(a)

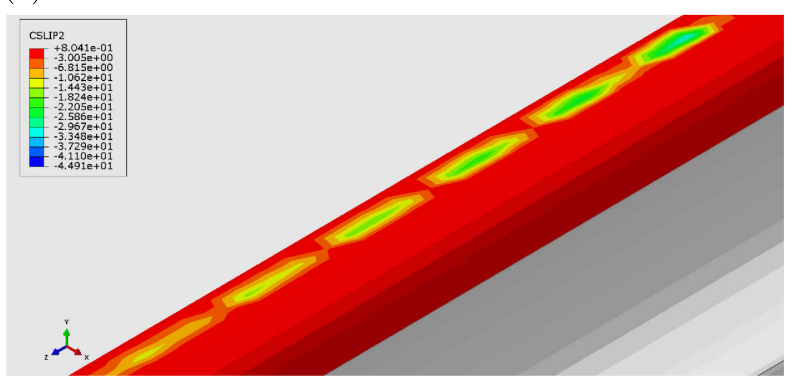

(b)

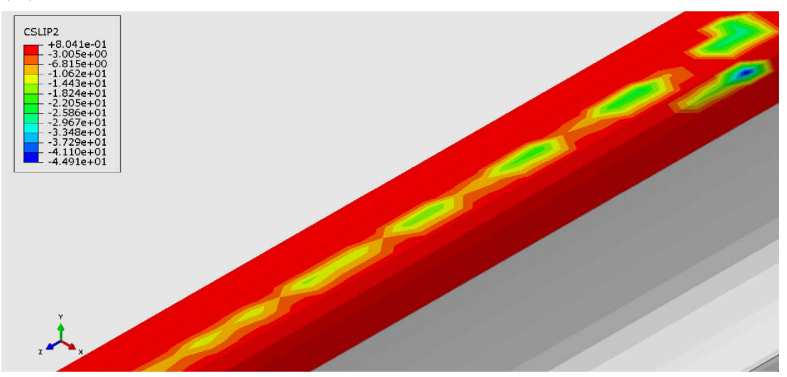

Fig. 4. Distribution of the slipping zone in the vertical direction of the rail section: (a) left rail, (b) right rail

movement), and the nephograms of slipping zones show the characteristics of large slipping in the center and small slipping around. It can be seen that the wear in the center of the slipping zone is larger than that in the surrounding zone, and the wear appears periodically, which is very similar to the phenomenon of rail corrugation on the measured line. At the same time, the distance between the centers of slipping zones is about $80 \mathrm{~mm}$, which is close to the wavelength range of $70-80 \mathrm{~mm}$ of the measured corrugation. On one hand, the calculation results directly verify the rationality and effectiveness of the finite element model of wheelset-track transient rolling contact in the time-domain. On the other hand, it also reflects that the formation of rail corrugation is caused by the periodic appearance of slipping zones of the wheel-rail contact surface. In order to further study the formation mechanism of rail corrugation, the cause of the periodic appearance of slipping zones are analyzed in detail in the following.

The existence of the slipping zone indicates that there is wheel slipping in the process of wheelset movement. When the wheel slips, the wheel-rail creep force will reach saturation. The publications (Wu et al., 2019, 2020a,b; Chen et al., 2010, 2020; Cui et al., 2016; Cui et al., 2017, 2018, 2019; Kurzeck, 2011) show that when the creep force between the wheel and rail reaches saturation, the wheel-rail system will have unstable vibration, that is, friction self-excited vibration, which leads to generation of rail corrugation. In order to explore stability of the wheel-rail system and better explain the rail corrugation phenomenon, the total energy of the system in the process of wheelset movement is analyzed, and the corresponding total energy output curve of the system is shown in Fig. 5. The analysis indicates that the energy of the wheelset-track system will fluctuate continuously during the vehicle braking process, which illustrates that the wheel-rail system is in an unstable state, that is, the wheel-rail system exhibiys unstable vibration in this process. Combined with the above publications, it can be seen that friction self-excited vibration of the wheelset-track system is the fundamental cause of rail corrugation in the measured section. In addition, different from the publications mentioned above, the wheel-rail creep force in this paper is not always in the saturated state at the vehicle braking stage, but presents a "saturated-unsaturated" periodic state, that is, the wheel is in a "slipping-rolling" periodic alternating state. The authors of this paper think that it is the "saturated-unsaturated" periodic characteristic of wheel-rail creep force that finally promotes the formation of rail corrugation. The reason why the wheel-rail creep force always remains saturated in the analysis included in the above publications may be related to the rigid wheel-rail (vehicle-track) model chosen.

Furthermore, in order to analyze the stress condition of the slipping zone, the determined node in the slipping zone is selected for research. The transverse and longitudinal friction shear stresses are shown in Fig. 6, in which the transverse direction represents the tangential direction of the rail section, and the longitudinal direction represents the vertical direction of the rail section (the direction of wheelset movement). It can be seen from Fig. 6 that when the wheel runs through the determined node, the friction shear stress curve presents large mutation. It is 


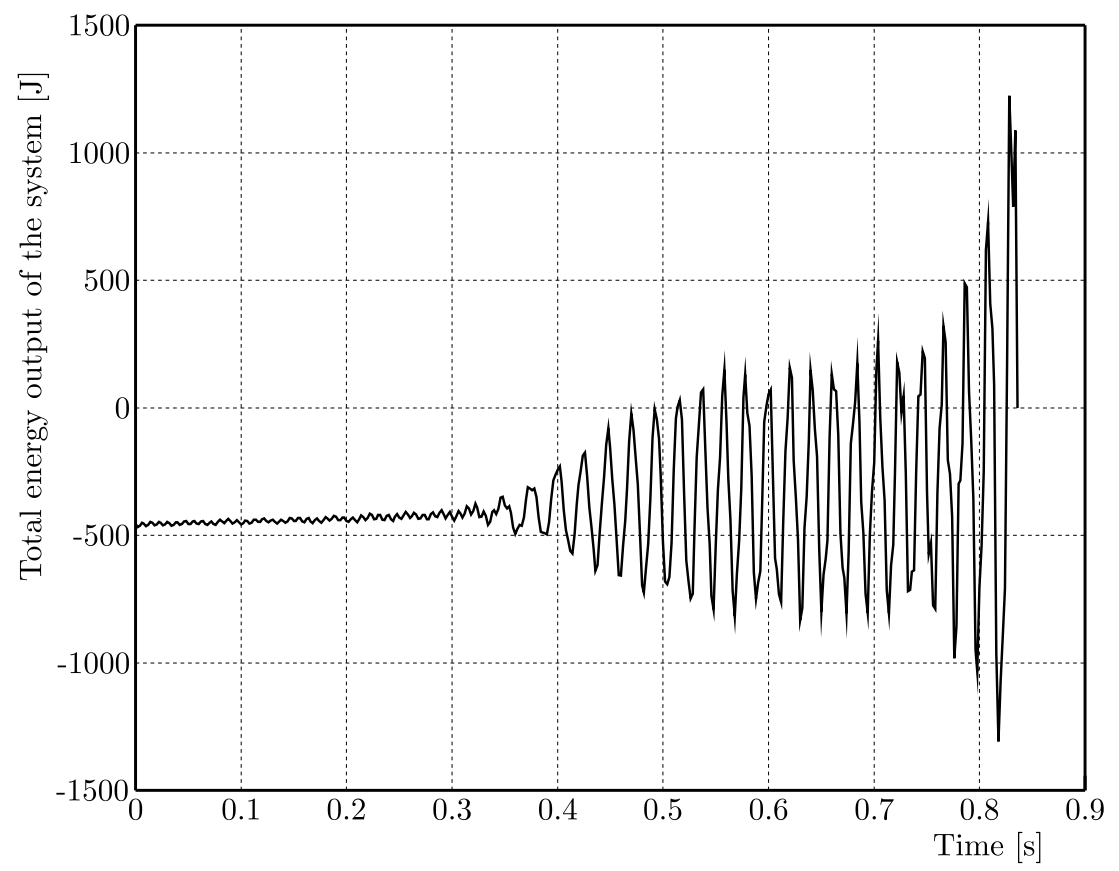

Fig. 5. Total energy output variation curve of the system

considered that the sharp increase of friction shear stress results in a large amount of slipping at the node, which eventually leads to an increase of wear. Meantime, according to Fig. 6, it can be seen that the longitudinal friction shear stress is much greater than the transverse friction shear stress, which is similar to the nephogram distribution of slipping zones shown in Fig. 4. This is mainly due to the line type. In actual operation, the wheel-rail transverse force on the tangential line is relatively small, while the longitudinal force is relatively large to provide braking.

(a)

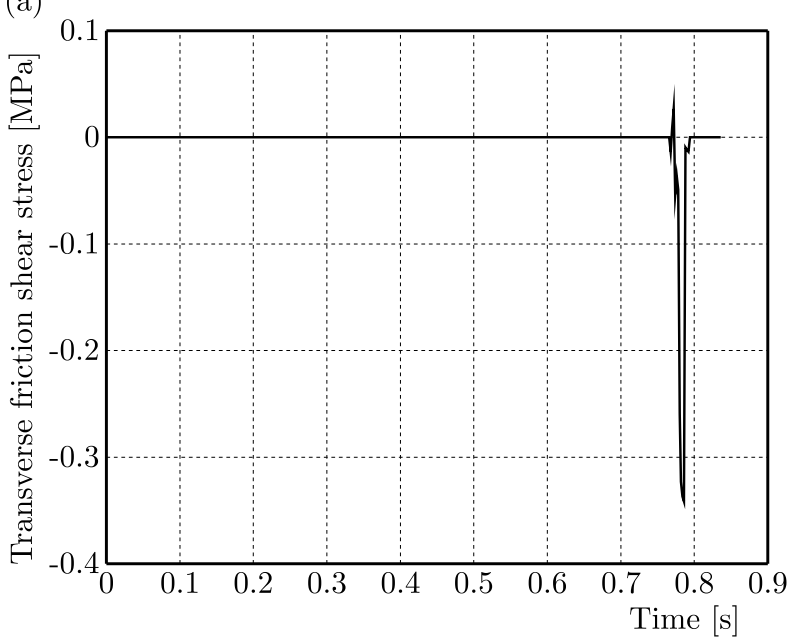

(b)

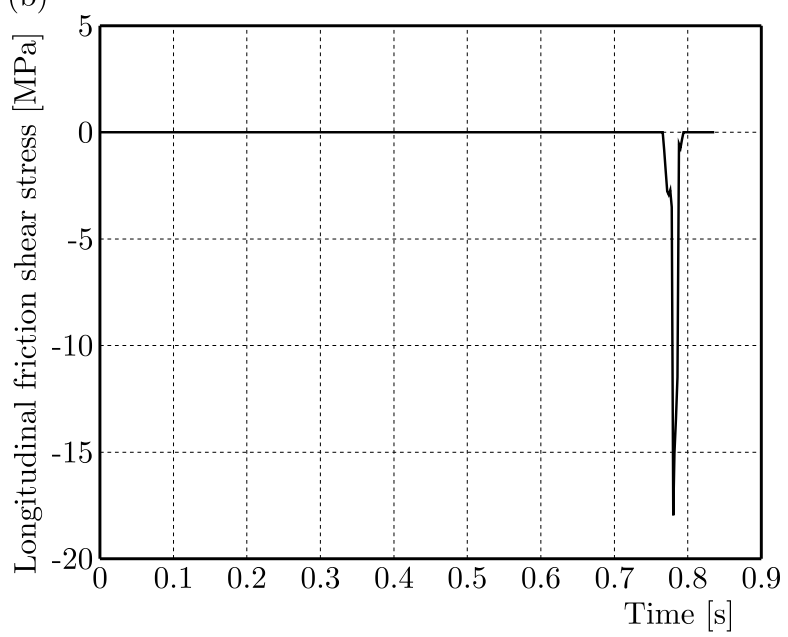

Fig. 6. Friction shear stresses: (a) transverse friction shear stress, (b) longitudinal friction shear stress

In order to comprehensively study the rail corrugation phenomenon, this Section also analyzes the time-domain dynamic responses of the wheel-rail system, and selects the vertical vibration accelerations of the determined nodes of the rail and wheel as the output variables. The corresponding variation curves are shown in Fig. 7. It can be seen from Fig. 7a that the response amplitudes of the rail vertical vibration acceleration reach the maximum when the wheel passes through the determined node, and the response amplitude of the rail vertical vibration 
acceleration at this time is much larger than that at other times. It can be seen from Fig. 7b that the wheel vertical vibration acceleration vibrates unsteadily at the braking stage, and the amplitudes of the oscillation are relatively large, which is similar to the variation trend of the total energy output curve of the system shown in Fig. 5, indicating that the unstable self-excited vibration of the wheel occurs during the braking process, and the unstable self-excited vibration eventually leads to the formation of rail corrugation.

(a)

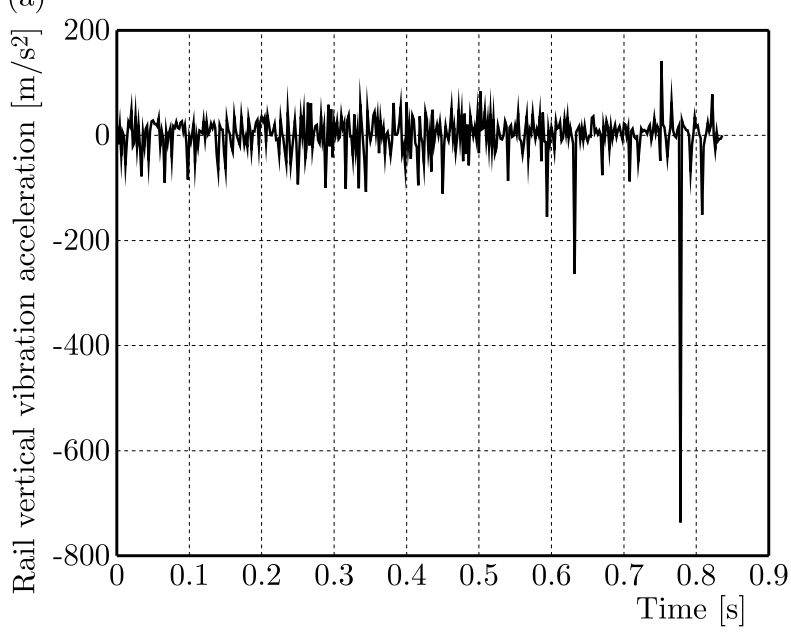

(b)

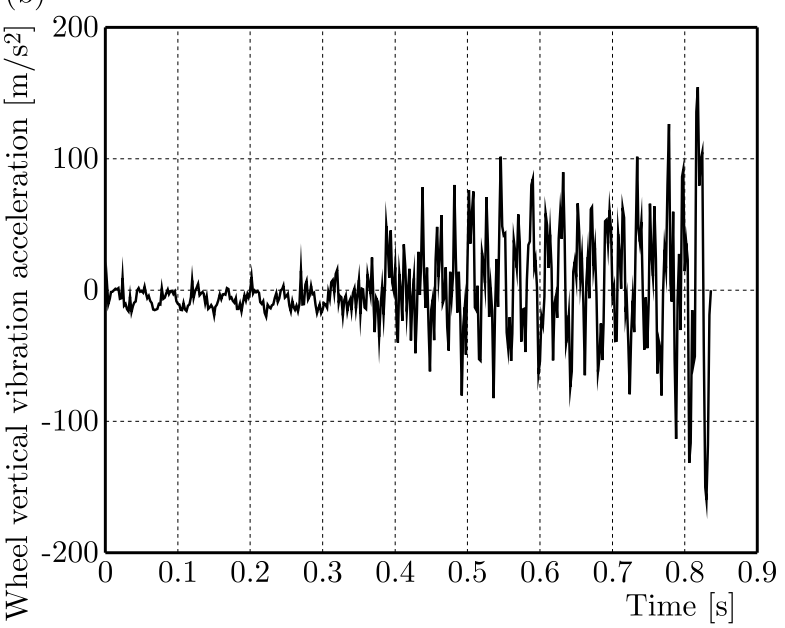

Fig. 7. Time-domain curves of vertical vibration accelerations: (a) rail vertical vibration acceleration, (b) wheel vertical vibration acceleration

\subsection{Analysis of frequency-domain characteristics}

The frequency-domain characteristics of dynamic responses of the wheel-rail system are analyzed through the frequency-spectrum transformation for the time-domain curves of vertical vibration accelerations of the rail and wheel as shown in Section 3.1. The corresponding frequency-domain curves of vertical vibration accelerations are shown in Fig. 8. It can be seen

(a)

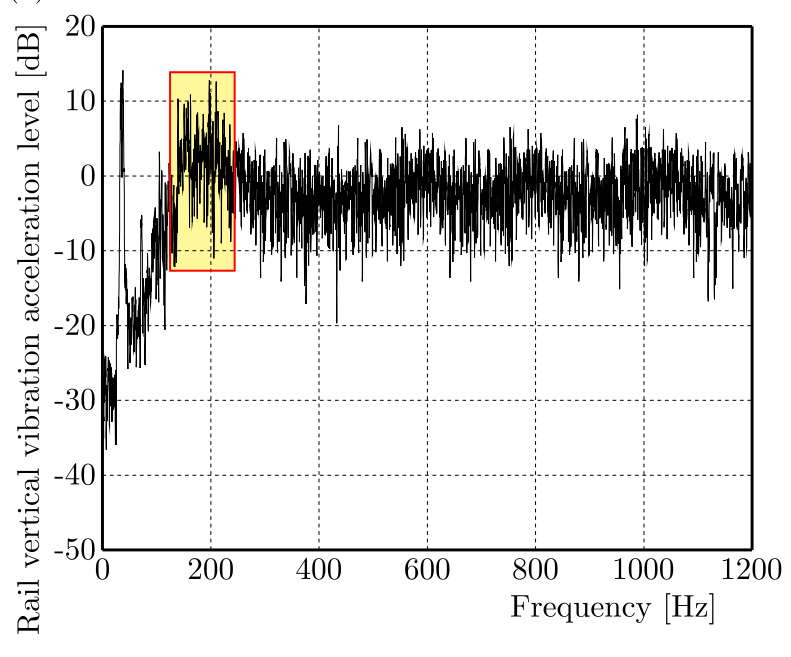

(b)

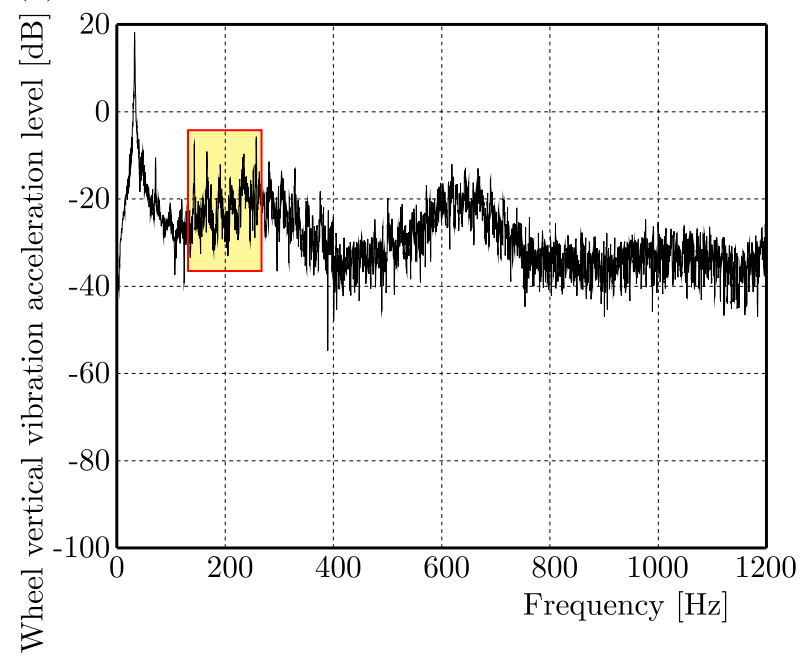

Fig. 8. Frequency-domain curves of vertical vibration accelerations: (a) rail vertical vibration acceleration, (b) wheel vertical vibration acceleration

that the vertical vibration acceleration levels of the rail and wheel show a peak region in the frequency range of $160-230 \mathrm{~Hz}$, which indicates that the resonance phenomenon of the wheel and 
rail may appear in the above frequency range, resulting in an increase of dynamic responses of the wheel-rail system. Meanwhile, the above frequency range is close to the characteristic frequency range of the field measured corrugation, which is $174-198 \mathrm{~Hz}$. Combined with the time-domain analysis, it can be further explained that the generation of rail corrugation is the wheel-rail resonance caused by the friction self-excited vibration of the wheelset-track system, and the rationality and validity of the model are also verified from the frequency-domain.

\section{Conclusions}

Taking the rail corrugation on the Cologne egg fastener tangential track near the entrance of a metro line in Shanghai as the research object, a three-dimensional solid wheelset-track transient rolling contact model is established by using the finite element software ABAQUS. Combined with the measured rail corrugation, the cause of rail corrugation is analyzed in the time-domain and frequency-domain, and the following conclusions can be drawn:

- In the process of vehicle braking, the quasi-periodic slipping zone will appear in the contact surface between the wheel and rail. It is found that the distance between the centers of slipping zones is close to the wavelength range of the measured corrugation, which reflects that the formation of rail corrugation is caused by the periodic appearance of slipping zones of the wheel-rail contact surface.

- The energy of the wheel-rail system will fluctuate continuously during the vehicle braking stage. Combined with the wheel-rail slipping analysis, it can be seen that the unstable friction self-excited vibration of the wheelset-track system is the fundamental cause of rail corrugation in the measured section, and it is precisely because of the "saturated-unsaturated" periodic characteristic of the wheel-rail creep force that finally forms rail corrugation.

- The results show that the vertical vibration acceleration levels of the rail and wheel have a peak region in the frequency range of $160-230 \mathrm{~Hz}$, and the frequency range is close to the characteristic frequency range of $174-198 \mathrm{~Hz}$ of the measured corrugation, which further illustrates that rail corrugation is caused by the wheel-rail resonance induced by the friction self-excited vibration of the wheelset-track system.

\section{Acknowledgements}

The author(s) disclosed receipt of the following financial support for the research, authorship, and/or publication of this article: National Natural Science Foundation of China (11772230).

\section{References}

1. Cai X.P., Zhong Y.L., Guo L.W., Tan X., 2019, Experimental study on effect of rail corrugation on structure vibration in egg fastener zone, Journal of Vibration, Measurement and Diagnosis, 39, $2,382-388+448-449$

2. Chatr N., Berg M., 2006, Simulation of vehicle-track interaction with flexible wheelsets, moving track models and field tests, Vehicle System Dynamics, 44, s1, 921-931

3. Chen G.X., Zhang S., Wu B.W., Zhao X.N., Wen Z.F., Ouyang H., Zhu M.H., 2020, Field measurement and model prediction of rail corrugation, Proceedings of the Institution of Mechanical Engineers, Part F: Journal of Rail and Rapid Transit, 234, 4, 381-392

4. Chen G.X., Zhou Z.R., Ouyang H., Jin X.S., Zhu M.H., Liu Q.Y., 2010, A finite element study on rail corrugation based on saturated creep force-induced self-excited vibration of a wheelset-track system, Journal of Sound and Vibration, 329, 22, 4643-4655 
5. Cui X.L., Chen G.X., Ouyang H., 2019, Study on the effect of track curve radius on friction-induced oscillation of a wheelset-track system, Tribology Transactions, 62, 4, 688-700

6. Cui X.L., Chen G.X., YAng H.G., 2017, Influence of wheelset structure and fastener stiffness on rail corrugation, Journal of Southwest Jiaotong University, 52, 1, 112-117

7. Cui X.L., Qian W.J., Zhang Q., Yang H.G., Chen G.X., Zhu M.H., 2016, Forming mechanism of rail corrugation of a straight track section supported by Cologne-egg fasteners, Journal of Vibration and Shock, 35, 13, 114-118+152

8. Cui X.L., Yan S., Chen G.X., 2018, Field measurement and numerical simulation for rail corrugation in sector of fixed dual short sleeper, Journal of Vibration and Shock, 37, 13, 171-176

9. Grassie S.L., 2009, Rail corrugation: characteristics, causes, and treatments, Proceedings of the Institution of Mechanical Engineers, Part F: Journal of Rail and Rapid Transit, 223, 6, 581-596

10. Grassie S.L., KalouseK J., 1993, Rail corrugation: characteristics, causes and treatments, Proceedings of the Institution of Mechanical Engineers, Part F: Journal of Rail and Rapid Transit, 207, 1, 57-68

11. Kurzeck B., 2011, Combined friction induced oscillations of wheelset and track during the curving of metros and their influence on corrugation, Wear, 271, 1, 299-310

12. LEI Z.Y., WANG Z.Q., 2020, Generation mechanism and development characteristics of rail corrugation of Cologne egg fastener track in metro, KSCE Journal of Civil Engineering, 24, 6, 1763-1774

13. Lei Z.Y., Wang Z.Q., Li L., Geng C.Z., 2019, Rail corrugation characteristics of the common fastener track in metro, Journal of Tongji University (Natural Science), 47, 9, 1334-1340

14. Li W., Du X., Wang H.Y., Wu L., Li X., Wen Z.F., Jin X.S., 2013, Investigation into the mechanism of type of rail corrugation of metro, Journal of Mechanical Engineering, 49, 16, 26-32

15. Li X., Li W., Shen Y.Y., Wen Z.F., Jin X.S., 2016, Study on the rail corrugation of the ladder-type sleepers track based on the track vibration theory, Journal of Mechanical Engineering, $\mathbf{5 2}, 22,121-128$

16. Li X., Ren Z.S., Xu N., 2017, Study on rail corrugation of steel spring floating slab track on subway with small radius curve track, Journal of the China Railway Society, 39, 8, 70-76

17. Liu W.F., Liu W.N., Wu Z.Z., Zhang H.G., 2015, Test study on treating rail corrugation for egg fastener in Beijing metro, Journal of Mechanical Engineering, 51, 21, 73-79

18. Liu W.F., Zhang H.G., Meng L., Wu Z.Z., Zhang H., 2016, A test of suppressing rail vibration by tuned rail damper for Beijing metro, Journal of Vibration Engineering, 29, 1, 105-111

19. PAn B., WAng A.B., GaO X.G., LiU L., 2020, Effects of lateral dynamic response characteristics of wheel-rail coupling systems on rail corrugation, Noise and Vibration Control, 40, 1, 132-137

20. WANG Y.R., Wu T.X., 2020a, Effects of vibration wave reflections between wheels and tracks with high-elastic fasteners on short pitch rail corrugation, Journal of Vibration and Shock, 39, 6, $29-36$

21. WAng Y.R., Wu T.X., 2020b, The growth and mitigation of rail corrugation due to vibrational interference between moving wheels and resilient track, Vehicle System Dynamics, 58, 8,1257-1284

22. WANG Z.Q., LEI Z.Y., 2020, Dynamic characteristics of a wheelset-track system under corrugation excitations in the metro operation process, Transactions of the Canadian Society for Mechanical Engineering, online, https://doi.org/10.1139/tcsme-2020-0132

23. Wen Z.F., 2006, Study on Rail Corrugation, Southwest Jiaotong University, Chengdu, China

24. Wu B.W., Chen G.X., Kang X., Zhu Q., 2020, Study on the origin of rail corrugation at a long downhill braking section based on friction-excited oscillation, Tribology Transactions, 63, 3, 439-452

25. Wu B.W., Chen G.X., Lv J.Z., Zhu Q., Kang X., 2020, Generation mechanism and remedy method of rail corrugation at a sharp curved metro track with Vanguard fasteners, Journal of Low Frequency Noise, Vibration and Active Control, 39, 2, 368-381 
26. Wu B.W., Chen G.X., Lv J.Z., Zhu Q., Zhao X.N., Kang X., 2019, Effect of the axlebox arrangement of the bogie and the primary suspension parameters on the rail corrugation at the sharp curve metro track, Wear, 426-427, B, 1828-1836

27. Wu Y., Han J., Zuo Q.Y., Jin X.S., Xiao X.B., Liang S.L., 2020, Effect of rail corrugation on initiation and development of polygonal wear on high-speed train wheels, Journal of Mechanical Engineering, 56, 17, 198-208

28. Yao H.M., Shen G., Gao L.J., 2018, Formation mechanism of worn profile rail corrugation based on experimental verification, Journal of Tongji University (Natural Science), 46, 10, 1427-1432

Manuscript received February 8, 2021; accepted for print July 22, 2021 